Article

\title{
Impact of Different Photovoltaic Models on the Design of a Combined Solar Array and Pumped Hydro Storage System
}

\author{
Hussein M. K. Al-Masri ${ }^{1, *(\mathbb{D})}$, Sharaf K. Magableh ${ }^{1}\left(\mathbb{D}\right.$, Ahmad Abuelrub $^{2}\left(\mathbb{D}\right.$, Osama Saadeh ${ }^{3}(\mathbb{D})$ \\ and Mehrdad Ehsani ${ }^{4}$ \\ 1 Department of Electrical Power Engineering, Yarmouk University, Irbid 21163, Jordan; \\ sharaf.magableh@outlook.com \\ 2 Department of Electrical Engineering, Jordan University of Science and Technology, Irbid 22110, Jordan; \\ amabuelrub@just.edu.jo \\ 3 Department of Energy Engineering, German Jordanian University, Amman 11180, Jordan; \\ osama.saadeh@gju.edu.jo \\ 4 Department of Electrical and Computer Engineering, Texas A\&M University, \\ College Station, TX 77843, USA; ehsani@ece.tamu.edu \\ * Correspondence: h.almasri@yu.edu.jo; Tel.: +962-2-7211111 (ext. 4658)
}

Received: 29 April 2020; Accepted: 18 May 2020; Published: 25 May 2020

\begin{abstract}
The impact of different photovoltaic models for a combined solar array and pumped hydro storage system was investigated. Al-Wehda dam located in Harta city in the northern of Jordan was used to validate the approach. The two-diode (TD), single-diode (SD), and ideal single-diode (ISD) solar models were evaluated in terms of the solar array size, reliability, and ecological effects. The impoundment of Al-Wehda dam was taken as the upper reservoir of the pumped hydro facility of the proposed renewable energy system. It was found that the PV power is more accurately modelled by considering the recombination loss in the TD solar model. This leads to a more realistic sizing and precise system evaluation. Results were obtained using the particle swarm optimization (PSO) algorithm and the whale optimization algorithm (WOA) for validation purposes. For instance, the PSO results showed that the realistic TD model is reliable, with an index of reliability of $98.558 \%$. Further, it is the most ecological solution with an annual emissions reduction of $21.5198 \mathrm{Gg}$. The optimized values are 44,840 solar panels and $65.052 \mathrm{M} . \mathrm{m}^{3}$ of the lower reservoir volume for the TD model. The number of PV panels are reduced by $16.67 \%$ and $7.93 \%$, respectively, with the ISD and SD relative to the TD model.
\end{abstract}

Keywords: two-diode PV model; reliability improvement; recombination PV model; realistic PV model; particle swarm optimization; whale optimization algorithm; pumped hydro storage; renewable energy system optimization; emissions reduction; uncertainty analysis

\section{Introduction}

Renewable power plants are the long-term solution for oil importing countries. This is especially true for countries struggling to satisfy their energy needs, such as Jordan. It is well known that photovoltaic (PV) renewable energy systems (RESs) are clean, modular, and quiet resources of energy. Further, the World Climate Conference that was held in Paris in 2015 set the limit for the global average temperature rise to be $0.2{ }^{\circ} \mathrm{C}$ per decade, between the years 2000 and 2100. Furthermore, hybrid systems that couple PV with other RES topologies have been considered worldwide [1-5]. Moreover, PV arrays, combined with an energy storage technology, such as pumped hydro storage (PHS), provide a reliable source of electricity [6-10]. Therefore, an in-depth investigation should be 
done to precisely model the PV array's output power. This will realistically estimate the capacity or number of PV panels of the solar PV array. Thus, more realistic construction decisions can be made. These will also include environmental and reliability analysis.

There are many models for the PV array to choose from when designing a system. These include the ideal single-diode (ISD), the single-diode (SD), and the two-diode (TD) models. The ISD is idealistic, as it ignores the series and leakage currents to ground losses. However, the SD model is described by five lumped parameters. These are light generated current, leakage or reverse saturation current, terminal voltage, series, and shunt resistances. However, SD is the most common model in RES-related studies, as it includes the aforementioned two losses [11]. However, the TD model introduces two more factors: The reverse saturation current of the second diode and the ideal second diode. In this case, a more complex model that has seven parameters is considered. This provides for a more detailed mathematical models to obtain more realistic I-V and P-V characteristic curves of a PV array [12-14].

The inclusion of the additional diode leads to a seven-parameter estimation problem. So, the complexity of this model is increased for estimating seven parameters instead of five as in the SD model [15]. However, the TD model is precise, leading to a true size for a hybrid renewable energy system (HRES) integration problem. It will give a more realistic computation for system performance, such as ecological and reliability indicators.

A lot of work has been done in the literature to model the PV panel output characteristics. In [16], the authors investigated the performance of the TD model in estimating the maximum power point for different PV technologies, such as string ribbon silicon, monocrystalline silicon, and thin film materials. In [17], the authors presented a theoretical model, offering a good compromise between the accuracy and simplicity of the parameters of the SD model. The model was developed using MATLAB for determining the solar PV module parameters to get the I-V characteristic curves of a PV module, string, and array. In [18], the authors presented the mathematical SD model of a PV module. The study includes the performance analysis of a $250 \mathrm{~W}$ PV module and its behavior with different temperature and irradiance values. The effects of varying shunt and series resistances were also considered. In [19], the authors presented a detailed explanation of various characteristics of ISD, SD, and TD-equivalent circuits. The non-linear mathematical equations were solved using the Newton-Raphson iterative method. This was to produce the I-V and P-V characteristic curves. It was concluded that TD model gives more precise characteristics of PV solar modules when compared to SD model results. However, this is at the expense of the complexity and number of iterations, due to the two more unknown parameters of the TD model.

Other studies investigated a power system that consists of both PV and PHS, using one of the three aforementioned PV models. In [20], a microgrid system including different power sources, such as wind turbine generators, PV, and storage batteries, is presented. The PV array was modeled using ISD, neglecting the temperature effect. The system cost with respect to the desired system reliability requirements was found. Furthermore, a compromise between cost and reliability, to find the optimum design of an autonomous hybrid generating system, using the particle swarm optimization (PSO) algorithm was achieved. In [21], the authors presented a method of controlling the load with the PSO technique for a smart micro grid. The PV system was designed using the ISD model. Moreover, the optimal size for system components was determined using the complex multi-objective optimization PSO method. In [22], the authors developed a model with several hybrid power schemes using the PSO algorithm. The output power of a PV array was estimated using the ISD model while neglecting the effect of temperature and using the irradiance on a horizontal surface instead of the incident irradiance values. However, they designed the system under different uncertainty scenarios, including load variation and reliability. In [5], the authors presented a method to optimize a hybrid solar and wind RES, combined with battery banks. The solar PV was modeled using ISD. The objective was to find the total cost of energy, using a stochastic gradient search optimization method. In [23], the researchers found the optimal energy management of an HRES. This system is composed of a hydropower plant combined with a solar PV, wind turbine, distribution generator, and battery bank as an energy storage 
system (ESS). Different load demand and weather conditions were studied with the aim of minimizing the system's operation cost. In [24], the authors presented an optimal energy management model of a standalone system, including a solar PV model using an ISD, diesel generator, and battery storage system. Their goal was to meet the load demand completely whilst satisfying the system constraints. In [25], the authors presented a method to find the optimal size for a hybrid solar PV and wind farm combined with battery storage. The PV output power was determined using the ISD-equivalent circuit. However, their goal was to minimize the total cost of the system, while maximizing power supply reliability. Furthermore, different constraints on the standalone system operation were considered while minimizing the fluctuations of power supplied to the utility grid. In [2], the researchers optimized a small-scale HRES using simulated annealing as a heuristics global approach. The system consists of solar and wind plants with batteries as ESS. The objective was to minimize the total cost of the HRES. Other reliability indicators, such as the loss of load probability (LOLP) and index of reliability (IR), were found at the optimum point in order to confirm the reliability of the system.

In summary, much of the research of HRES studies use the ISD or SD models for PV system design, for simplicity. However, the PV system designed in this paper was done using three different PV models for comparison purposes on a power system level. In other words, the PV plant, in this investigation, was modelled using the ISD, SD, and TD models. Then, the plant size, the index of reliability (IR), and detailed reliability results were computed for a grid-connected system, for each PV model for comparison purposes. It was shown that the TD solar model provides realistic and accurate sizing of the PV array, and hence the size and reliability of the entire system can be precisely found.

In this paper, an on-grid system including a PV array combined with PHS, as shown in Figure 1, was optimized using the PSO algorithm and whale optimization algorithm (WOA). The main components of the grid-connected system include the PV array, PHS sub-system showing the upper and lower reservoir, AC and DC bus with the appropriate power electronics converters, and the load demand, which is connected to the AC bus.

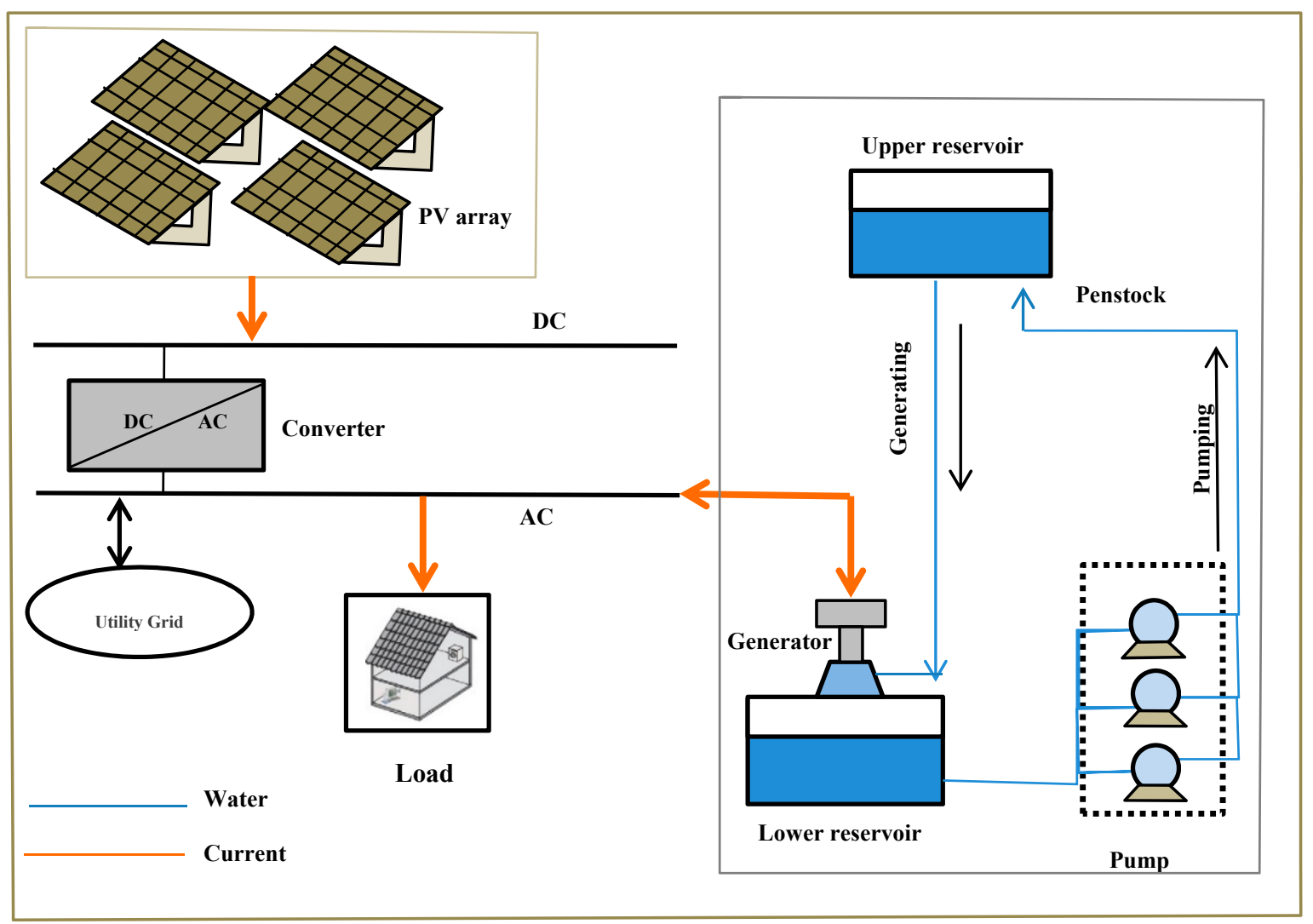

Figure 1. An on-grid photovoltaic (PV) array combined with pumped hydro storage (PHS) system. 


\section{System's Measured Data}

Hourly data is required to run the optimization algorithms for the RES shown in Figure 1. The data was taken in 2018 for Harta city in the north of Irbid, Jordan, as shown in Figures 2 and 3, respectively. The sample time of the data acquisition is one hour. Note that the optimization algorithms are hourly testing the system in order to find the optimal system's configuration. Further, the duration of campaign acquisition for the measured data was one year, i.e., $8760 \mathrm{~h}$.
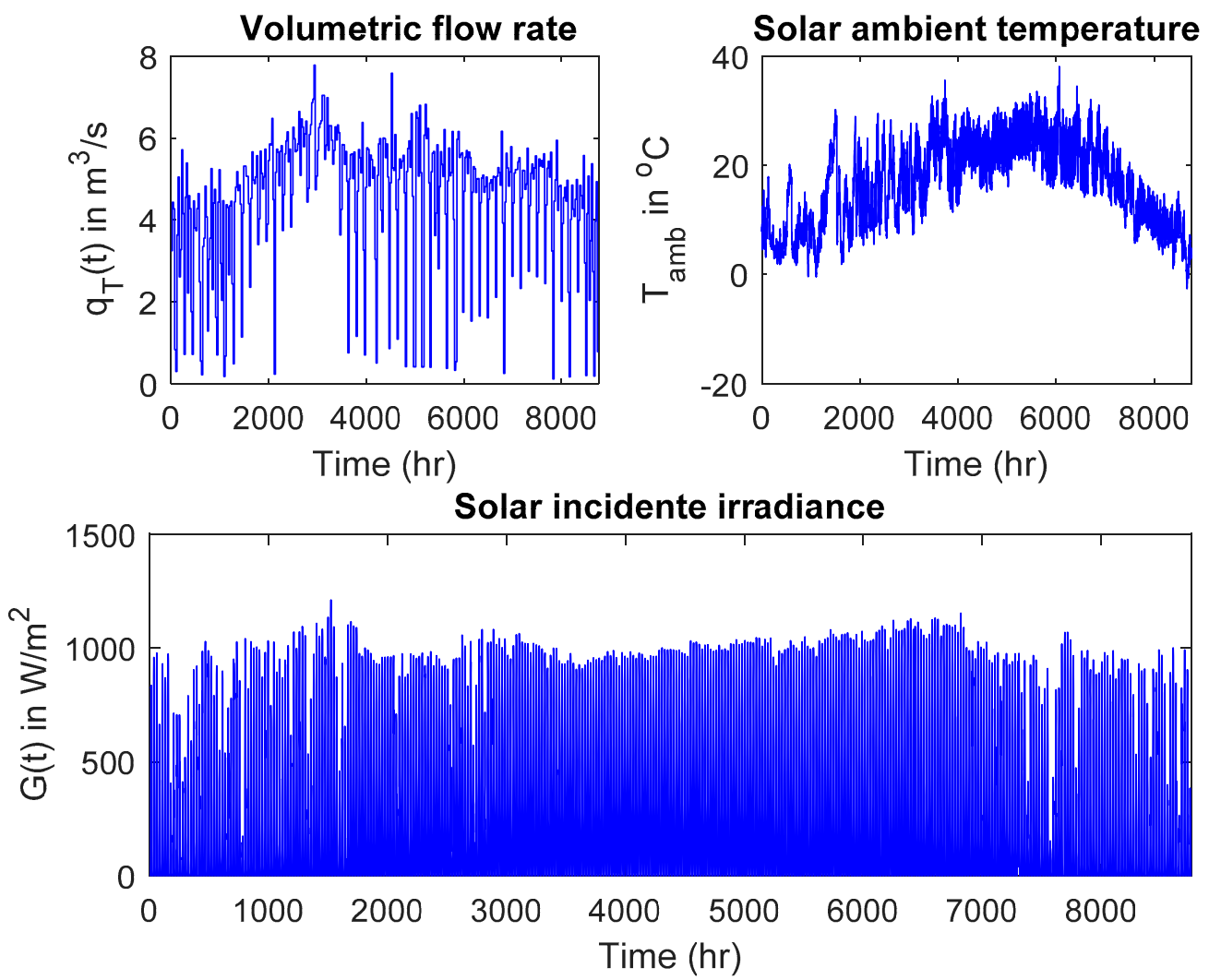

Figure 2. Hourly measured solar and hydro data in 2018 for Harta city, northern Irbid, Jordan.

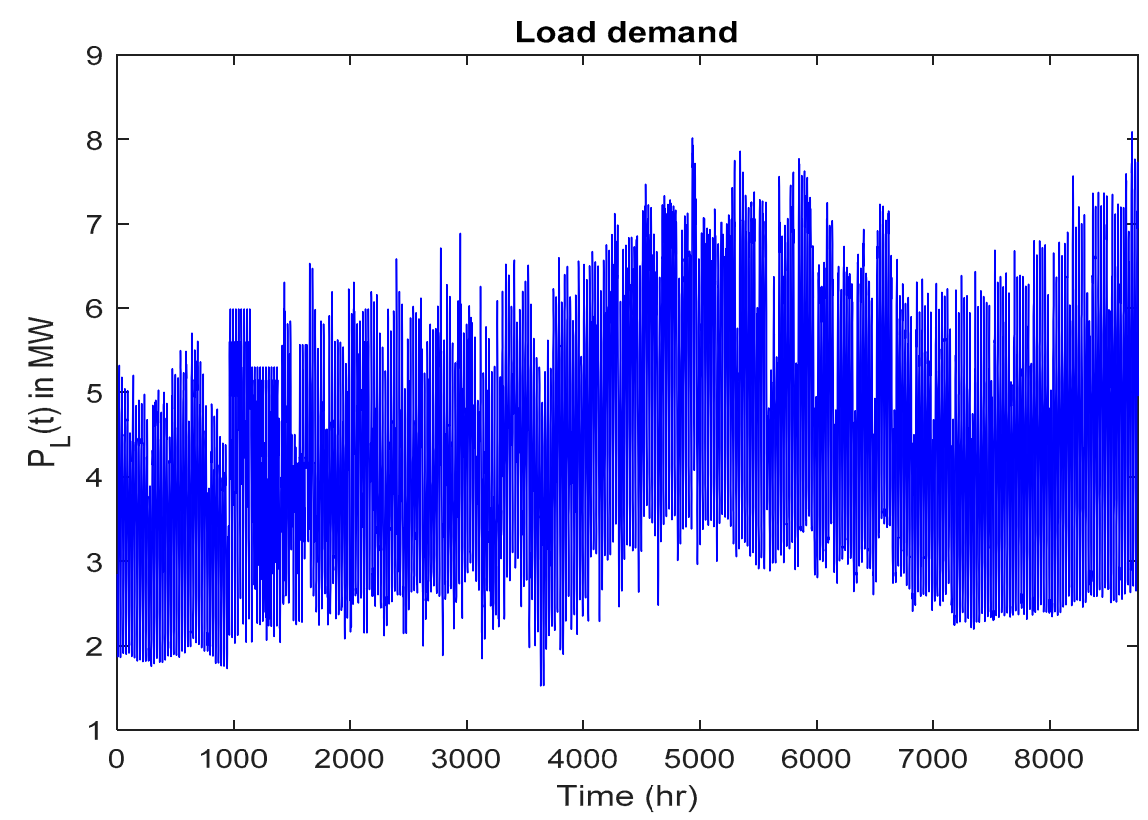

Figure 3. Hourly measured load demand in 2018 for Harta city, north of Irbid, Jordan. 
The measured load demand (in MW) was obtained from the Jordanian National Electric Power Company (NEPCO), which is responsible for the availability and safety of power transmission. Further, the volumetric flow rate (in $\mathrm{m}^{3} / \mathrm{s}$ ) input values into the PHS unit for Al-Wehda Dam was obtained from the Jordan Valley Authority (JVA). JVA is responsible for the public water supply, wastewater services, and development of water resources and dams in Jordan. Moreover, the solar incident irradiance, $G(t)$ in $\mathrm{W} / \mathrm{m}^{2}$, and the solar ambient temperature, $T_{a m b}(t)$ in ${ }^{\circ} \mathrm{C}$, were obtained from the royal scientific society (RSS), which is responsible for testing services locally and internationally. Note that $G(t)$ and $T_{a m b}(t)$ are used to compute the photo current $\left(I_{P h}\right)$ of the solar module as discussed in [6]. It is worth noting that the solar ambient temperature is the temperature of the solar panel surroundings. They were measured in front of the solar panel. Furthermore, RSS performs research studies related to RES in Jordan, such as the optimal tilt angle of a fixed PV array. Note that the designed PV array is to be positioned toward south in a fixed position. A tilt angle of $28^{\circ}$ is optimal for PV installation in Jordan [26]. Note that the three institutions provided the hourly data, shown in Figures 2 and 3, after requesting official letters from the employer of the authors.

\section{Mathematical Modeling and Design Methodology}

In order to truly size HRES, the proper design of the PV system is important to determine the correct number of PV modules [15]. Therefore, a basic introduction of the principles of PV cells and their mathematical relations is essential. Therefore, modelling and simulation of the PV modules and arrays are presented here.

As was mentioned, the objective of this work was a comparative analysis of the ISD, SD, and TD models of the PV module in a PV array, combined with PHS. This is to enhance the conversion efficiency of power from the PV system. For this, the optimal system size, ecological impact, and reliability will be studied in the three PV scenarios.

\subsection{Modeling of a PV Array Output Power Generation}

The PV cell is a semiconductor device whose p-n junction is exposed to light, which produces an electric current [27]. However, the design of the PV system depends on the load power. The mathematical models and the corresponding circuit models for ISD, SD, and TD, are investigated here. Furthermore, the physical behavior of each model and their characteristic solar curves are studied.

\subsubsection{ISD Model}

This model is the most simplified form of an ideal PV module as shown in Figure 4. The output current as a function of the voltage is expressed by (1) [28]:

$$
I=I_{P h}-I_{o}\left(e^{\left(\frac{V}{\alpha V_{T}}\right)}-1\right)
$$

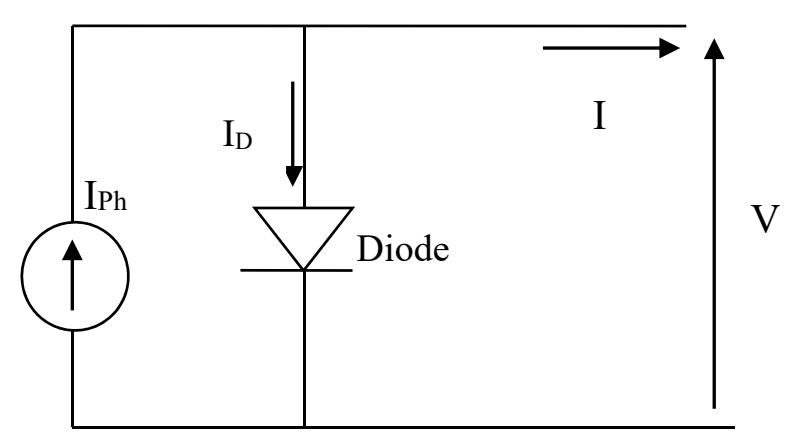

Figure 4. Equivalent circuit of a photovoltaic (PV) panel using ideal single diode (ISD). 
However, this model does not provide accurate and realistic I-V and P-V characteristics. This is because Equation (1) does not represent the actual characteristics due to neglecting the two diode losses. Actual PV modules are composed of several connected PV cells, in series with losses associated with leakage currents to the ground. These losses are modelled by a series resistance $\left(R_{s}\right)$ and a shunt resistance $\left(R_{\text {sh }}\right)$, which will be presented in Section 3.1.2.

\subsubsection{SD Model}

The SD circuit model of a PV panel is shown in Figure 5. In the literature $[2,4,21,27,29,30]$, this is also called a five-parameter model. The model takes into account the series and leakage current to ground losses, which were not considered in the ISD model. They are represented by the series and shunt resistances $R_{S}$ and $R_{s h}$.

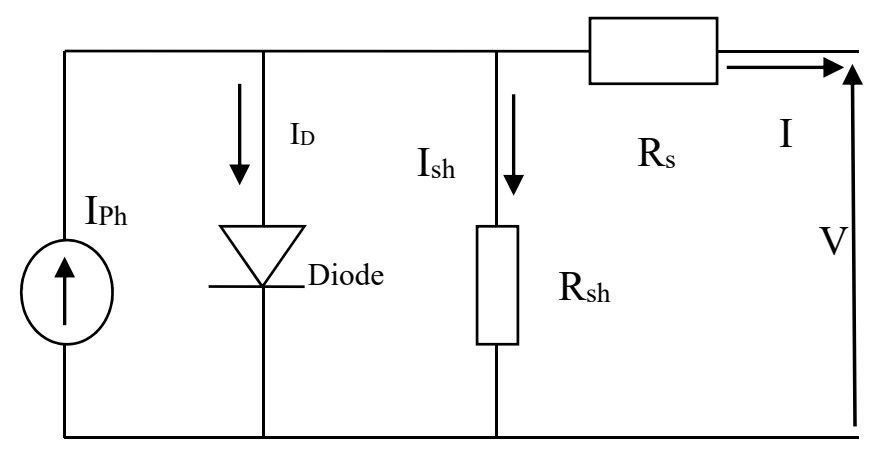

Figure 5. Equivalent circuit of a PV panel using the single diode (SD) model.

The shunt resistance, $R_{s h}$, is inversely proportional to the leakage current to the ground, and usually has a large value. Resistor $R_{S}$ represents the series current losses and the internal resistance of the PV module and is, by design, very small. The PV cells are added together to form a PV module and then interconnected in parallel series to form a PV array [17,31].

This model has been used in grid-connected and standalone PV systems [17,31]. This model is based on the well-known Shockley diode equation, which is also known as the five-parameter model. The relationship between the output current (I) and voltage (V) of the PV panel for a single unit, according to the SD model is expressed by (2) [6,32]:

$$
I=I_{P h}-I_{o}\left(e^{\left(\frac{V+I R_{s}}{a V_{T}}\right)}-1\right)-\frac{V+I R_{s}}{R_{s h}}
$$

The five key parameters, $I_{p h}, I_{0}, R_{s}, R_{s h}$, and $V_{T}$, are given under standard test conditions (STCs) which are $1 \mathrm{~kW} / \mathrm{m}^{2}$ air mass 1.5 (AM1.5) and $25^{\circ} \mathrm{C}$. These parameters can be computed using analytical or numerical solutions, based on the specifications provided by the manufacturer. Further, $I_{P h}, I_{0}, V_{T}$, and $I_{o_{s t c}}$ are given in $[6,17,33]$.

However, the SD model neglects the recombination losses of the diode, which is a phenomenon that should be considered to accurately model a PV panel. The single diode model assumes a constant value for the ideality factor. The ideality factor is a measure of how closely the diode follows the ideal diode Equation of the diffusion process [27,34]. It is usually considered as a function of the voltage across the device. Furthermore, at high voltage recombination in the device, electron-hole pairs are dominant at the surface of the bulk regions. This means that the ideality factor is close to one. However, at lower voltages, recombination in the junction dominates and the ideality factor approaches two [34]. The two exponential diodes model (i.e., TD model) takes into account the recombination phenomena and will be discussed in Section 3.1.3. 


\subsubsection{TD Model}

The TD model, shown in Figure 6, of a PV panel takes into account both the diffusion and the recombination processes by including diodes $D_{1}$ and $D_{2}$ [35]. The first diode $\left(D_{1}\right)$ simulates the diffusion process of the minority carriers into the depletion layer, while diode $\left(D_{2}\right)$ represents the recombination in the space charge region of the P-N junction [36].

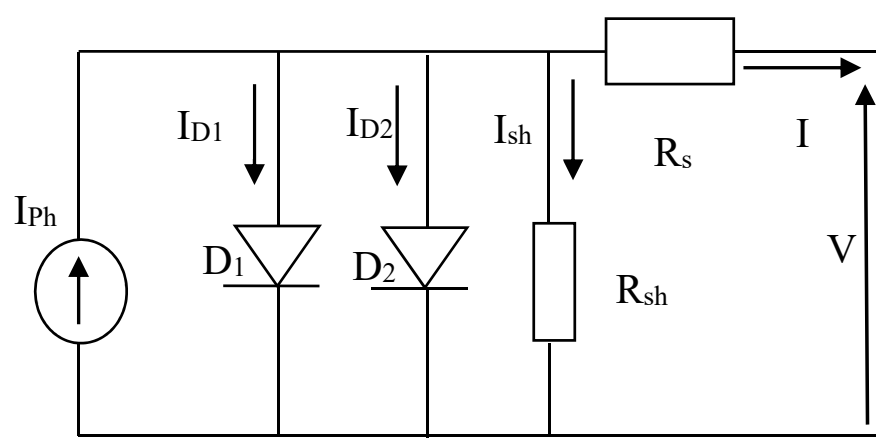

Figure 6. Equivalent circuit of a PV panel using the TD model.

The TD model is a modified and improved version of the SD circuit. The SD circuit did not take into account the effect of recombination as shown in Figure 5. Many RES studies use the SD model for a PV system design $[2,4,21,29,30]$. However, the TD model is more realistic and accurate, because it takes into account both the diffusion effects and recombination losses. This results in a more precise and realistic mathematical description of a solar panel and leads to a correct size for the PV array and also the size, ecological impact, and reliability of the entire system [14-16].

After adding a second diode $\left(D_{2}\right)$ in parallel with the first one $\left(D_{1}\right)$, Equation (2) becomes as shown in Equation (3) $[37,38]$. The values of $I_{D 1}, I_{D 2}$, and $I_{S h}$ are computed as in $[12,16,37]$. Thus, the output PV current for the TD model is updated to be as in Equation (3):

$$
I=I_{P h}-I_{o_{1}}\left(e^{\left(\frac{V+I R_{s}}{\alpha_{1} V_{T}}\right)}-1\right)-I_{O_{2}}\left(e^{\left(\frac{V+I R_{s}}{\alpha_{2} V_{T}}\right)}-1\right)-\frac{V+I R_{S}}{R_{s h}}
$$

The optically generated current of the PV module is linearly dependent on the solar irradiance and is also influenced by temperature, according to the $I_{P h}$ Equation found in $[6,14,38]$. The hourly measured values of the solar irradiance and ambient temperature are depicted in Figure 2.

The diode $\left(D_{1}\right.$ or $\left.D_{2}\right)$ saturation currents $I_{01}$ or 2 depend on the temperature and can be expressed as shown in [16,37].

Some research studies provide another approach to get the value of the saturation current of $D_{1}$ or $D_{2}$ in the TD model. In fact, the diode saturation current is very small and to simplify the model, in these studies, both of the reverse saturation currents $I_{o_{1}}$ and $I_{o_{2}}$ were set equal as in $[16,37,38]$.

The diode ideality factors $\alpha_{1}$ and $\alpha_{2}$ represent the diffusion effects and recombination losses. The recombination has an impact on both the short circuit current and open circuit voltage. The recombination region should be minimized in order to ensure that the $\mathrm{p}-\mathrm{n}$ junction is convenient to collect the light generated current, and to minimize the losses in the current due to recombination. So, the recombination is a negative effect, and thus, it is a loss. Regarding the diffusion effect, the carrier must be generated within a diffusion length of the junction, so that it will be able to diffuse to the junction before recombining. When a carrier exists with a concentration in the semiconductor, it will move from the higher to the lower concentration area in the diffusion process. The impact of diffusion on the solar cell, will increase the carrier concentrations in a device with time. Additionally, a low diffusion length means that minority carriers disappear from the junction edge quickly due to recombination, thus allowing more carriers to cross and increasing the forward bias current. Consequently, to minimize recombination and achieve a high voltage, a high diffusion length is required. So, the diffusion and 
recombination effects are interrelated. However, the aforementioned models (i.e., SD and ISD), do not take into account the recombination losses as the TD model does, which is a physical phenomenon.

In accordance with Shockley's diffusion theory, $\alpha_{1}$ is unity [14,37,39]. However, the value of $\alpha_{2}$ is flexible. It was found that if $\left(1.2 \leq \alpha_{2} \leq 2\right)$, the best match between their proposed model and the practical I-V curve is obtained. These studies state that $\frac{\alpha_{1}+\alpha_{2}}{P}=1$ and $\alpha_{1}=1$. It follows that the variable $P$ can be chosen to be greater than or equal to 2.2 and less than 3 . Under the aforementioned considerations, $I_{0}$ can be simplified as in $[14,37,39]$.

\subsubsection{Solar Array Model}

A single PV panel does not produce enough power to satisfy common applications. A configuration of cells is called a module. In other words, a panel consists of one or more PV cells assembled and pre-wired for field installation [37]. A similar series-parallel configuration of PV panels composes the array or a solar PV plant. The wattage rating of a PV array is usually the maximum DC power output under STC. Figure 7 represents the circuit model of TD for the solar PV array.

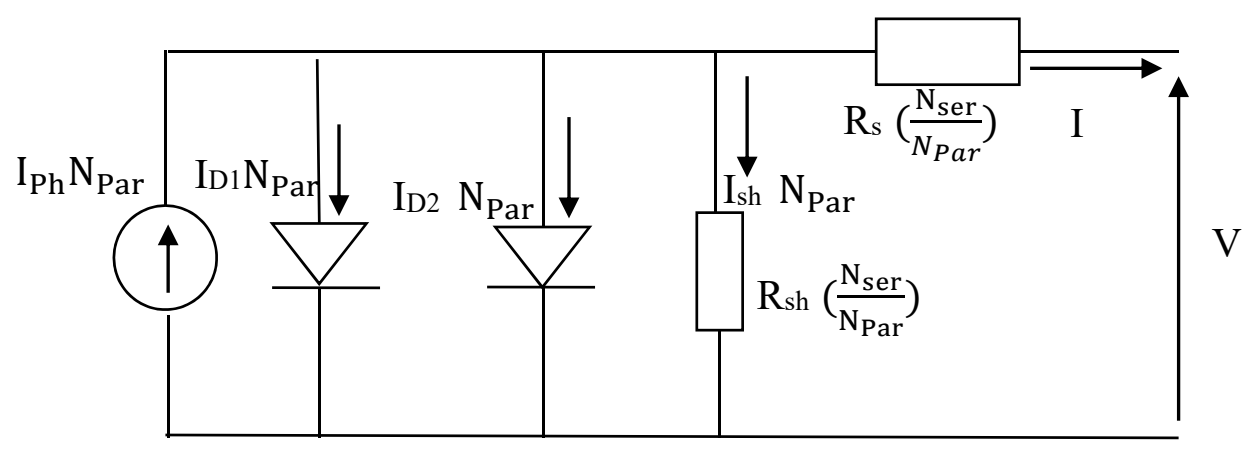

Figure 7. Equivalent circuit of a PV array using the TD model.

A PV array is composed of a number of strings connected in parallel $\left(N_{P a r}\right)$. The number of PV modules connected in series per string is $\left(N_{s e r}\right)$. Note that $\left(N_{P a r} \times N_{s e r}\right)$ is the number of PV modules $\left(N_{P V}\right)$ of the PV array, which is one of the design variables to be optimized by using the proposed methodologies and optimization algorithms in Sections 3.4.3-3.4.5, respectively. The optical and saturation currents for a PV array can be expressed as in [16].

The formula that describes the relationship between the output current (I) and voltage (V) of a PV array is derived as in $[6,37,39]$. The output power from a PV array can be obtained as shown in Equation (4). Moreover, the values of the series and parallel resistances of the PV array are given by the equations described in [16]:

$$
P=V I=N_{\text {Par }} I_{P h} V-N_{\text {Par }} V\left(\sum_{n=1}^{2} I_{o n}\left(e^{\left(\frac{1}{\alpha_{n} V_{T}}\right)\left(\frac{V}{N_{s e r}}+\frac{I R_{s}}{N p a r}\right)}-1\right)\right)-\frac{N_{\text {Par }}}{R_{p}} V\left(\frac{V}{N_{\text {ser }}}+\frac{I R_{s}}{N_{\text {Par }}}\right)
$$

\subsection{Characteristics of a PV Panel}

In order to accurately size hybrid renewable energy systems (HRESs), including a solar PV array combined with pumped hydro storage, the proper design of the PV system is important to determine the realistic number of PV modules [17]. A "KC200GT" polycrystalline PV panel was considered in this paper. Table 1 presents the characteristics of this $\mathrm{PV}$ panel as provided by the manufacturer. Further, the I-V and P-V characteristic curves of the mentioned PV panel for the ISD, SD, and TD models were simulated as shown in Figure 8. 
Table 1. Datasheet of the selected PV module.

\begin{tabular}{cc}
\hline Parameters (KC200GT Datasheet) & Value \\
\hline Open circuit voltage $\left(V_{o c}\right)$ & $32.9 \mathrm{~V}$ \\
Short circuit current $\left(I_{s c}\right)$ & $8.21 \mathrm{~A}$ \\
Maximum power at STC $\left(P_{\max }\right)$ & $200.143 \mathrm{~W}$ \\
No. of Cells in series & 54 \\
Temperature coefficient of $V_{o c}$ & $-0.35502 \mathrm{~V} /{ }^{\circ} \mathrm{C}$ \\
Temperature coefficient of $I_{s c}$ & $0.06 \mathrm{~A} /{ }^{\circ} \mathrm{C}$ \\
Maximum Power Voltage $\left(V_{m p p}\right)$ & $26.3 \mathrm{~V}$ \\
Maximum Power Current $\left(I_{m p p}\right)$ & $7.61 \mathrm{~A}$ \\
Diode ideality factor $\left(\alpha_{1}\right)$ & 0.97736 \\
Diode ideality factor $\left(\alpha_{2}\right)$ & 1.2 \\
Light-generated current $\left(I_{L}\right)$ & $8.2288 \mathrm{~A}$ \\
Shunt resistance $\mathrm{R}_{\text {sh }}(\mathrm{ohms})$ & $150.6921 \Omega$ \\
Series resistance Rs $($ ohms $)$ & $0.34483 \Omega$ \\
Efficiency & $16 \%$ \\
\hline
\end{tabular}
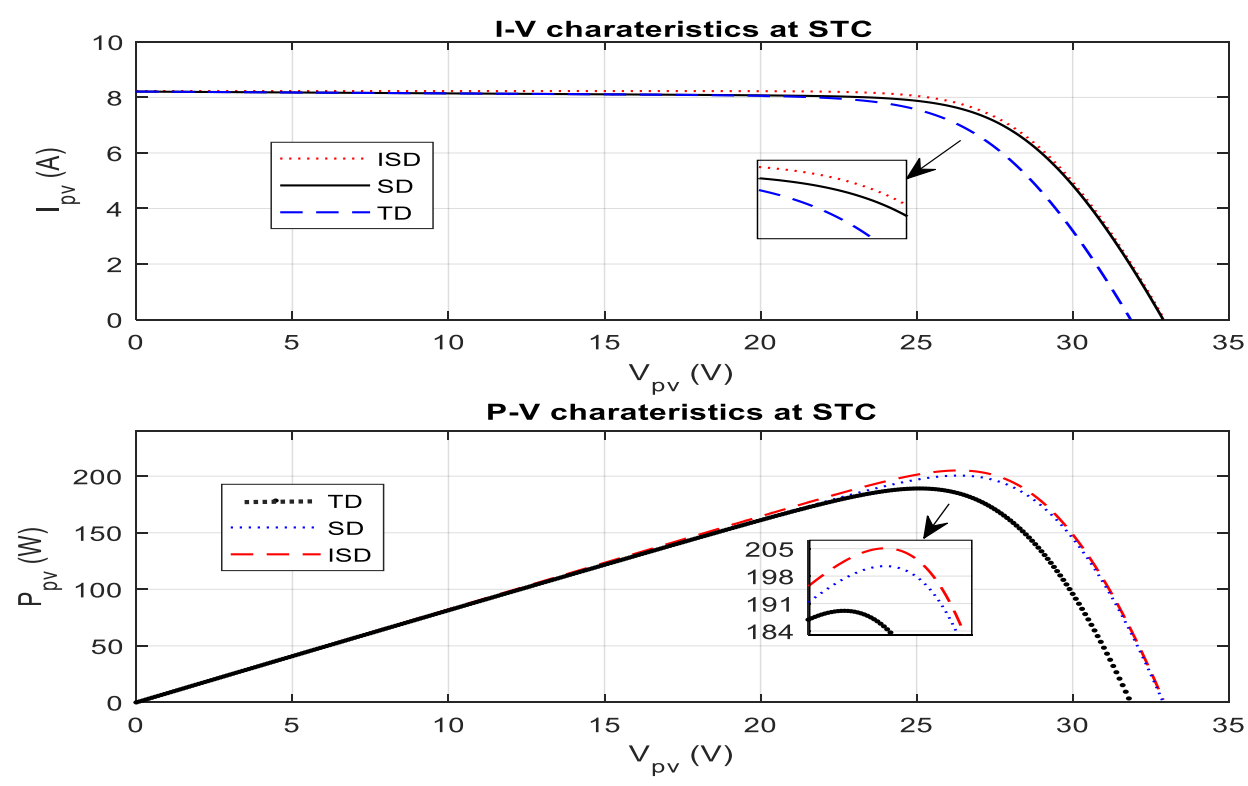

Figure 8. Current-Voltage (I-V) and Power-Voltage (P-V) characteristic curves of the solar PV selected module at standard test conditions (STC).

Here, $25{ }^{\circ} \mathrm{C}$ is considered as a special case in Figure 8 in order to depict the $\mathrm{I}-\mathrm{V}$ and $\mathrm{P}-\mathrm{V}$ characteristics under standard test conditions (STCs), and to show the differences between the ISD, SD, and TD photovoltaic models. Moreover, Figure 8 shows that for a single PV panel, the power that can be extracted is $189.149 \mathrm{~W}$ in the case of the TD model. This power increases by $8.43 \%$ with the ISD model. So, the TD model gives more realistic and accurate results because it takes into account the realistic phenomenon of recombination losses. This will lead to a true size of the HRES, especially with the large-scale power system, whose load is shown in Figure 3.

In summary, many RES studies use the ISD model for PV system design [32,33]. However, the TD model (shown in Figure 6) is more accurate, because it takes into account both the diffusion and the recombination effects. This results in a more precise mathematical description of the solar panel, leading to a true size of the PV array and true reliability and environmental estimates of the entire system [17]. 


\subsection{Modeling of Hydropower Facilities}

There can be different topologies for a PHS system. However, the volume of the reservoir and the head elevation are the essential design parameters [40]. Other parameters of the PHS, such as the penstock and the selection of pumps and turbines, are more important in the mechanical design [41]. In this paper, the Al-Wehda impoundment was assumed to be the UR of the PHS energy system in this study. This dam is near Harta city, in northern Jordan. The actual head of this dam is $110 \mathrm{~m}$. In this design, the volume of the lower reservoir (LR) of the PHS is one of the design variables to be optimally determined in order to truly size the hydro power plant facility. The two main operating modes to be considered in the energy management strategy and the mathematical modeling of the PHS system are the generating (discharging) and the pumping (charging) modes.

\subsubsection{Generating (Discharging) Mode}

In this paper, a PHS plant was operated based on the hourly measured volumetric flow rate $\dot{q}_{T}(t)$, as seen in Figure 2, so that the peak periods of load demand can be satisfied. This is due to the flexibility and the fast response of the PHS plant in serving the load and pumping. This PHS system is combined with a PV array to get a reliable resource of energy suppling the load demand of Harta shown in Figure 3. When the PV power is insufficiently satisfying the load demand, the discharging mode starts, and water will be released down from the upper reservoir to the turbine. The output from the hydro turbine generating unit can be expressed using Equations (5) and (6) [40]:

$$
\begin{gathered}
P_{T}(t)=\eta_{T} \rho g h \cdot \dot{q}_{T}(t)=C_{T} \cdot \dot{q}_{T}(t) \\
C_{T}=\eta_{T} \rho g h
\end{gathered}
$$

\subsubsection{Pumping (Charging) Mode}

This mode is in effect when there is surplus power from the PV array. The water will be pumped to the upper reservoir of Al-Wehda dam. Therefore, the flow rate of water extracted from LR in the charging mode can be expressed as shown in Equations (7) and (8) [6]:

$$
\begin{gathered}
q_{p}(t)=\eta_{P} \cdot \frac{P_{P V_{P}}(t)}{\rho g h}=C_{P} \cdot P_{P V_{P}}(t) \\
C_{P}=\frac{\eta_{P}}{\rho g h}
\end{gathered}
$$

\subsubsection{Modeling of a PHS Plant}

In order to model the PHS system, the quantity of water stored in LR must be known. The water quantity at time $t$ is determined as shown in Equation (9) [6,8]. The water level in the LR can be modelled by the percentage of water in the LR $(P O W)$, which is between 0 and 1 and it is calculated using Equation (10):

$$
\begin{gathered}
V_{L R}(t)=V_{L R}(t-1)(1-\sigma)+q_{\text {discharge }}(t)-q_{\text {charge }}(t) \\
P O W(t)=\frac{V_{L R}(t)}{V_{L R_{\max }}}
\end{gathered}
$$

The volume of water of the PHS plant expressed in Equation (9) is subject to the constraints in Equation (11). The optimal value of $V_{L R}$ is also subject to the constraint $P O W$ as shown in Equation (12). Thus, the energy balance in Equation (20) will be optimally met in every time step [8]:

$$
\begin{aligned}
V_{L R_{\min }} & \leq V_{L R} \leq V_{L R_{\max }} \\
\frac{V_{L R_{\min }}}{V_{L R_{\max }}} & \leq P O W \leq 100 \%
\end{aligned}
$$




\subsection{System Design Methodology}

Numerous PV renewable energy studies and existing methodologies use only one solar model, which is the ISD or SD model in their studies. However, in our approach, designing the PV plant was done three times using three different PV models, ISD, SD, and TD. In this case, a comprehensive methodology was performed in this paper in comparison with other existing methodologies that use only one solar PV model. Furthermore, a detailed comparison in Section 4.1 for both PSO and WOA optimization algorithms for the three aforementioned PV models will be shown.

\subsubsection{System Reliability}

Reliability evaluation is considered as a good measure for the planning and operation stages of the power system, by precisely computing many reliability indices [42]. These performance indices evaluate the process of meeting the load demand for an HRES. Reliability is a major concern to meet the load demand over a given time period. This is due to the irregular nature of the power supply of RES, which significantly influences the HRES power generation and supply. This will also impact the load demand in standalone and on-grid HRES applications [5].

In many studies, the reliability of the system is taken as either a constraint or a goal to be achieved in the optimization process. In this paper, the value of the index of reliability (IR), shown in Equation (13) [5,29], will be optimized using the PSO algorithm and WOA to find the optimal size of the HRES configuration. Other reliability indices, such as loss of power supply probability (LPSP), loss of load probability (LOLP), and energy expected not served (EENS), will be computed corresponding to the optimal value of IR.

Here, LPSP is the probability, over a given time period, in which the power demand is not fully satisfied by the generated power. It is widely used in the literature to assess the system reliability due to the RES' intermittent nature. It is mathematically represented as shown in Equation (14) for a one-hour time step $[29,30]$. Furthermore, the power system reliability can be evaluated based on the LOLP index. The LOLP index is defined as the total failure hours of the energy deficit divided by the number of sample hours for the entire period, which is $8760 \mathrm{~h}$ for the year of 2018 in this paper [43]. This index is widely used in order to evaluate whether the system is able to serve the load demand, by indicating the percentage of time that the system is insufficient at supplying the load. This index can be computed as shown in Equation (15) [6,25]. Moreover, EENS is a probabilistic index for the reliability analysis of a power system. It represents the expected energy not supplied to the load due to the energy deficit as in Equation (16) [5,44]:

$$
\begin{gathered}
I R=1-\frac{\sum_{t=1}^{8760}\left[P_{L}(t)-P_{G}(t)\right]}{\sum_{t=1}^{8760}\left[P_{L}(t)\right]} \\
L P S P=\frac{\sum_{t=1}^{8760}\left[P_{L}(t)-P_{G}(t)\right]}{\sum_{t=1}^{8760}\left[P_{L}(t)\right]} \\
L O L P=\frac{\sum_{t=1}^{8760} \text { hours }\left[\left(P_{P V_{L}}(t)+P_{T}(t)\right)<P_{L}(t)\right]}{8760} \\
E E N S=\sum_{t=1}^{8760}\left[P_{L}(t)-P_{G}(t)\right]
\end{gathered}
$$

\subsubsection{Ecological Impacts}

The indirect and direct anthropogonic greenhouse gases (GHG) have been estimated to be 28,717 gigagrams in Jordan. A national inventory was performed by the Jordanian Ministry of Environment to estimate the GHG emissions in Jordan in 2006 [45]. 
Equation (17) is used to compute the total amount of GHG emissions. This is done for each $\mathrm{kWh}$ purchased from the grid and contains conventional brown energy sources [46]. Table 2 shows the constants used to compute emissions in Jordan:

$$
G H G=\frac{E_{b r o w n} \times E F}{1-L}
$$

Table 2. Emission constants data in Jordan.

\begin{tabular}{cc}
\hline Parameters & Value \\
\hline T\&D losses $(\%)$ & $14.57 \%$ \\
Electricity emission factor $\left(\mathrm{tCO}_{2} / \mathrm{MWh}\right)$ & 0.6439 \\
\hline
\end{tabular}

Another indicator for the GHG emission is the emissions reduction, which represents the difference between the baseline and the project emissions, as shown in Equations (18) and (19):

$$
\begin{gathered}
E R=\text { Base }_{\text {emission }}-\text { Project }_{\text {emission }} \\
\text { Base }_{\text {emission }}=E_{\text {renewable }} \times E F
\end{gathered}
$$

The baseline emission is the amount of emissions generated by the grid-connected power plants when generating the same amount of power as the RES. The project emission is defined as the amount of emission generated by the RES, such as solar and hydro. This indicator is considered zero for the applicable RES projects.

\subsubsection{System Operation and Optimization}

The objective of the system optimization in this paper was to determine the optimal reliable system configuration. The objective function is the index of reliability (IR). Further, the decision variables are the number of PV modules $\left(N_{P V}\right)$ and the volume of the lower reservoir $\left(V_{L R}\right)$, with respect to technical constraints. Moreover, PSO and WOA are hourly testing of all possible configurations in order to meet the load consumption and determines the one that has the optimal value of IR. The energy balance Equation of the entire system is hourly tested and is expressed by Equation (20):

$$
P_{P V}(t) N_{P V} f_{P V} \eta_{i n v}+P_{T}(t)+P_{\text {grid }_{(\text {Brown })}}(t)=P_{P V P}(t)+P_{L}(t)+P_{\text {grid }_{(\text {sales })}}(t)
$$

The system operation flow chart is shown in Figure 9. It describes the energy management strategy of the two modes of operation. In other words, it traces hydro operation with respect to PV generation as modelled by the energy balance Equation of Equation (20). Furthermore, Figure 9 helps researchers to simply follow the design methodology and the operation strategy modeling of the system described in Figure 1. 


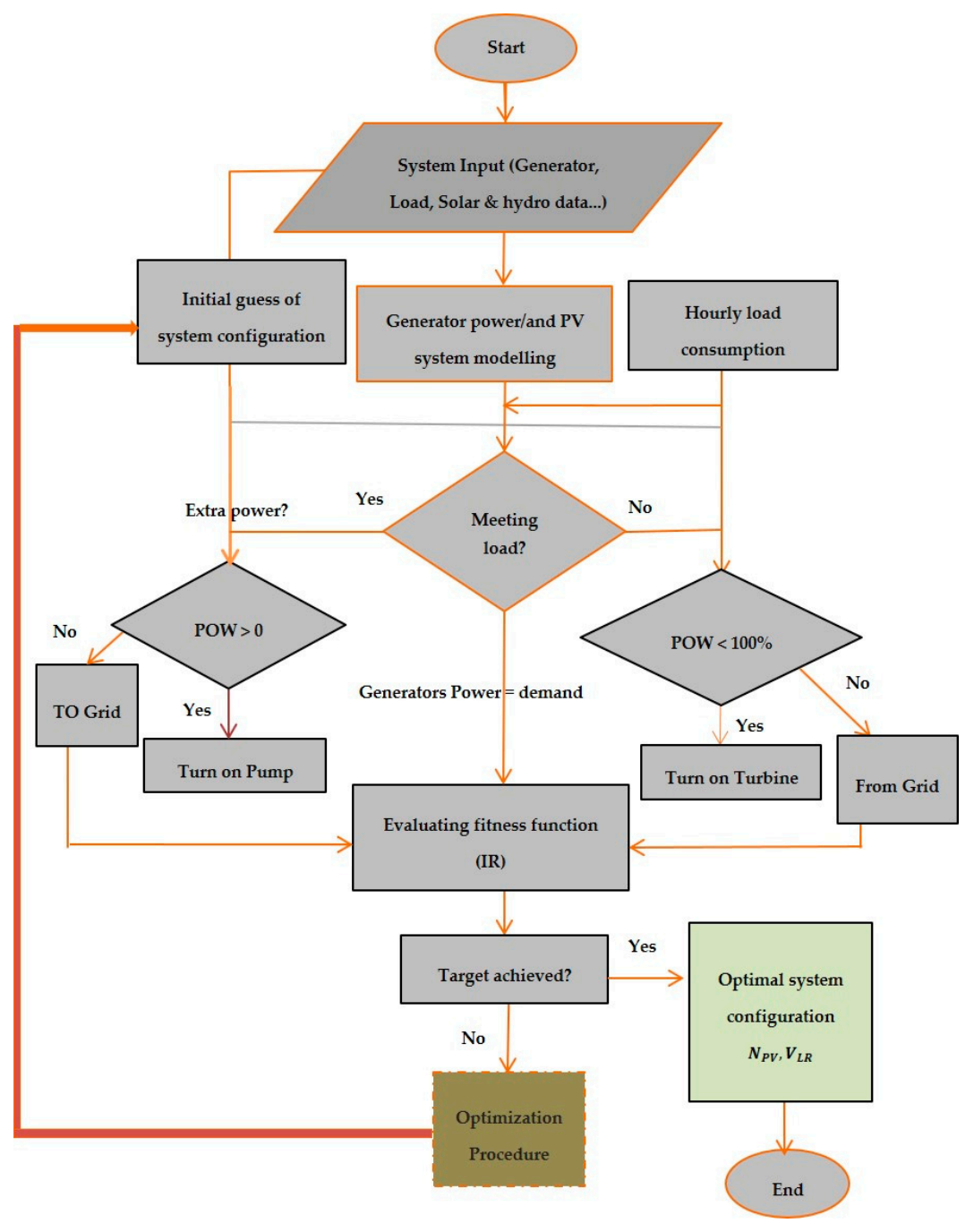

Figure 9. System operation flow chart for an on-grid system.

\subsubsection{Particle Swarm Optimization (PSO) Algorithm}

The PSO algorithm is one of the popular nature-inspired metaheuristic optimization algorithms. It was developed by James Kennedy and Russell Eberhart in 1995 [47]. Moreover, it has been revitalized several times in order to solve practical issues related to engineering and power system optimization [48-50]. Recently, PSO has emerged as one of the promising algorithms in solving various optimization problems in the field of science and engineering as well [51-55].

As such, PSO is inspired by the social and cooperative behavior displayed by various species to look for their needs in the search space. The algorithm is guided by personal experience $\left(P_{\text {best }}\right)$, overall experience $\left(G_{b e s t}\right)$, and the present movement of the particles to decide their next positions in the search space. Further, the experiences are accelerated by two factors $c_{1}$ and $c_{2}$, and two random numbers generated between $[0,1]$. Whereas, the present movement is multiplied by an inertia factor, $w$, varying between $\left[w_{\min }: w_{\max }\right]$. 
The initial population (swarm) of size $N$ and dimension $D$ is denoted by $X=\left[X_{1}, X_{2}, \ldots, X_{N}\right]^{T}$. Each individual (particle) is given by $X_{i}=\left[X_{i, 1}, X_{i, 2}, \ldots, X_{i, D}\right]$. Additionally, the initial velocity of the population is denoted by $V=\left[V_{1}, V_{2}, \ldots, V_{N}\right]^{T}$. The index $i$ varies from 1 to $N$ whereas the index $j$ varies from 1 to $D$. The velocity and position of the particles are computed using Equations (21) and (22), respectively [56]:

$$
\begin{gathered}
V_{i, j}^{k+1}=w V_{i, j}^{k}+c_{1} r_{1}\left(\text { Pbest }_{i, j}^{k}-X_{i, j}^{k}\right)+c_{2} r_{2}\left(\text { Gbest }_{j}^{k}-X_{i, j}^{k}\right) \\
X_{i, j}^{k+1}=X_{i, j}^{k}+V_{i, j}^{k+1}
\end{gathered}
$$

\subsubsection{Whale Optimization Algorithm (WOA)}

The WOA is one of the nature-inspired meta-heuristic optimization algorithms. It simulates the social behavior of humpback whales. It imitates the bubble-net hunting mechanism of humpback whales. It was proposed by Mirjalili and Lewis in 2016 [57]. WOA is designed based on the spiral bubble-net feeding strategy, which is mathematically modelled in order to perform optimization.

Humpback whales recognize the prey's location and surround them. The WOA algorithm presume that the current supreme candidate solution is the targeted victim, or it is close to the optimal solution. After the supreme search is determined, the whales update their positions towards the supreme search. This behavior is given by Equation (23) and the position vector is computed as in Equation (24) [57]:

$$
\begin{gathered}
\vec{D}=\left|\vec{C} \cdot \vec{X}^{*}(n)-\vec{X}(n)\right| \\
\vec{X}(n+1)=\overrightarrow{X^{*}}(n)-\vec{A} \cdot \vec{D}
\end{gathered}
$$

where $n$ is the iteration's number and $\vec{X}^{*}$ is the position vector of the obtained best solution until now. Note that this position is updated at each iteration if there is a superior solution. Furthermore, $\vec{A}$ and $\vec{C}$ are coefficients of the vectors and can be computed as in [57].

\section{Results and Discussion}

The mathematical models, design, simulation, methodology, and optimization algorithms were implemented to supply the load demand of Harta city, north of Irbid in Jordan. The average load was $4.067 \mathrm{MW} /$ day, with a total energy of $38.3475 \mathrm{GWh}$ in 2018. The hourly load values are shown in Figure 3.

Note that the results were obtained and computed using Matlab software. This was done after converting the energy management and operation strategy, shown in Figure 9, of our PV array combined with PHS grid-connected system into a Matlab code. Then, both the PSO algorithm and WOA were run with the inputs of the hourly measured data in 2018 shown earlier in Figures 2 and 3. Afterwards, the optimal value of the index of reliability (IR) was found for each PV model. Further, the corresponding detailed reliability results were computed at the optimal value of IR.

\subsection{Impacts of PV Modeling}

The variations of the objective function of IR as a percentage \%, using PSO and WOA, are shown in Figures 10 and 11, respectively. Figure 10 shows that the PSO optimal values of IR are $98.553 \%$, $98.527 \%$, and $98.558 \%$ for the ISD, SD, and TD, respectively. Furthermore, the WOA optimal values of IR are $98.557 \%, 98.524 \%$, and $98.565 \%$, respectively, for the ISD, SD, and TD solar models. It can be noticed that the optimization results are approximately the same for the two algorithms. Further, the percentage difference between the PSO and WOA solutions is negligible. This means that the PSO and WOA are very close to the global optimum solution. Table 3 shows the corresponding decision 
variables of the system configuration at the optimal value of IR. The number of generations of PSO or WOA is 100 for all cases.

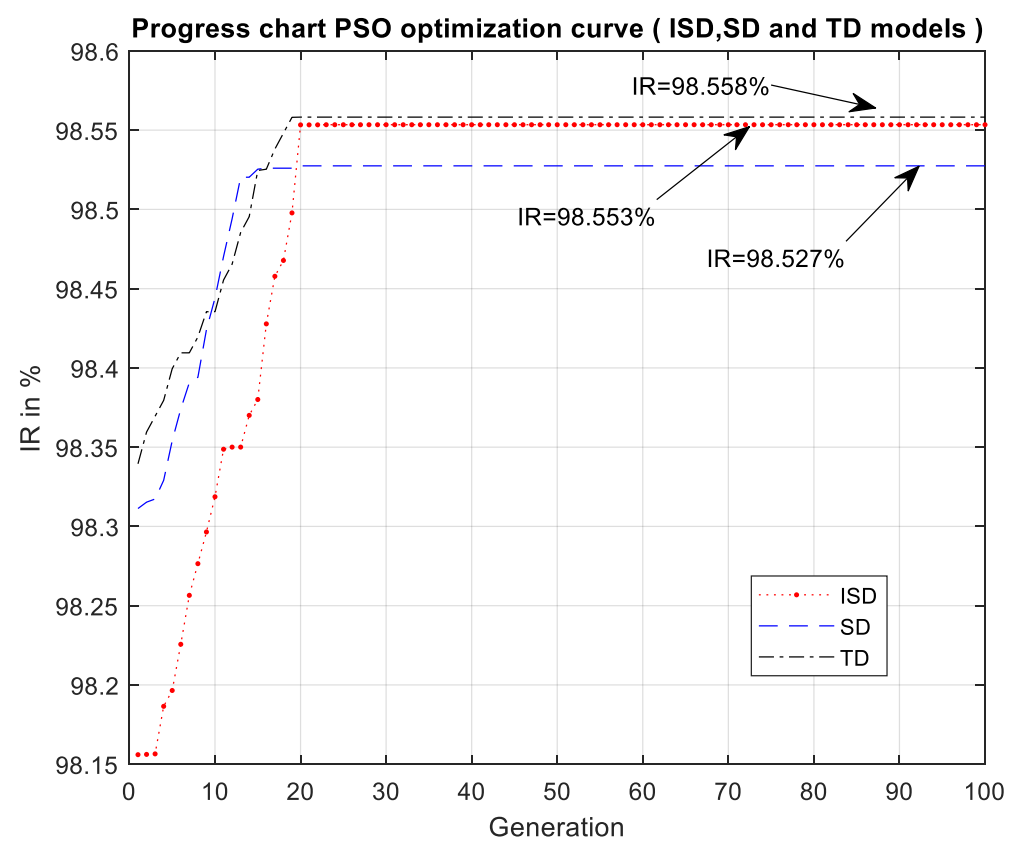

Figure 10. Progress charts of index of reliability (IR) in \%, using particle swarm optimization (PSO) for the ideal single diode (ISD), single diode (SD), and two diode (TD) models.

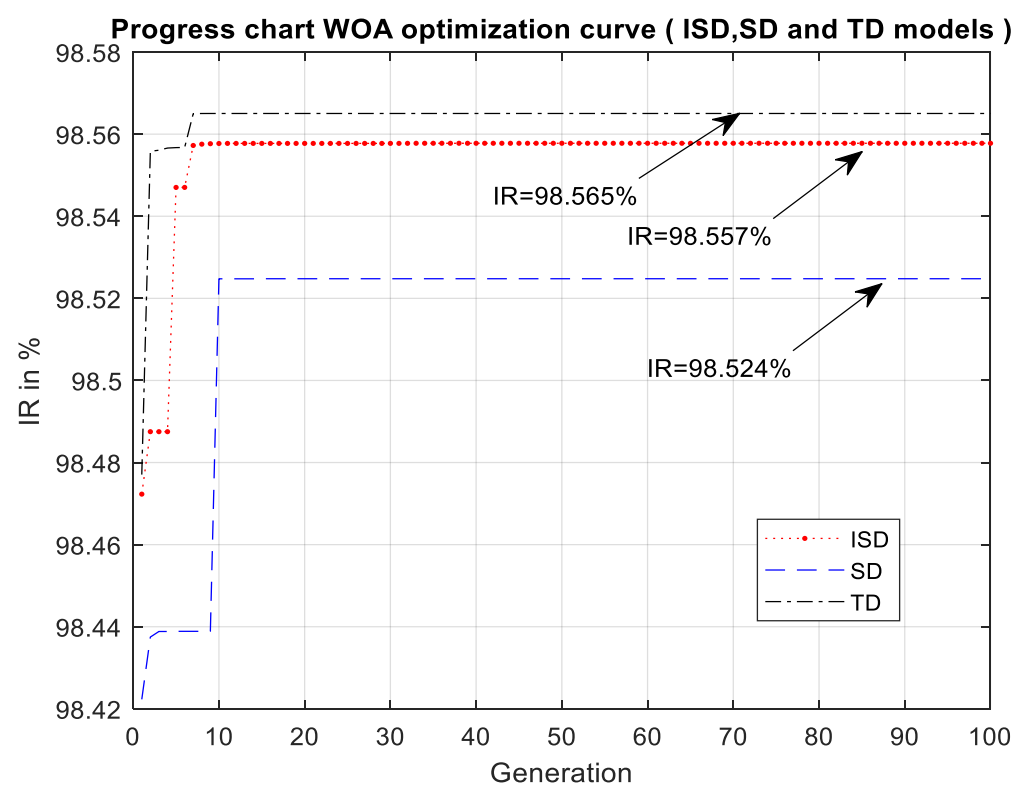

Figure 11. Progress charts of IR in \%, using whale optimization algorithm (WOA) for the ISD, SD, and TD models.

Table 3. System's sizing at the optimal value of IR in each case.

\begin{tabular}{ccccccc}
\hline System's Configuration & \multicolumn{2}{c}{ TD } & \multicolumn{2}{c}{ SD } & \multicolumn{2}{c}{ ISD } \\
\hline Optimization Algorithm & PSO & WOA & PSO & WOA & PSO & WOA \\
\hline Index of Reliability IR in \% & 98.558 & 98.565 & 98.527 & 98.524 & 98.553 & 98.557 \\
Number of PV panels (N $\left.{ }_{\text {PV }}\right)$ & 44840 & 44618 & 41286 & 39369 & 37365 & 36701 \\
Volume of the LR $\left(\mathrm{V}_{\mathrm{LR}}\right)$ in M-m & 65.052 & 65.272 & 64.956 & 65.0012 & 64.747 & 66.7121 \\
\hline
\end{tabular}


It can be seen that there is a slight difference in the value of IR obtained by PSO and WOA in the ISD, SD, and TD models. However, the TD model has the highest value of IR. This is because the TD model takes into account the recombination losses, which implies the need for more PV to satisfy the load demand. So, neglecting the recombination losses in both ISD and SD models will actually increase the number of solar panels, i.e., the size of the PV array. The percentage decrease of the number of PV panels is $16.67 \%$ and $7.93 \%$ for the ISD and SD models for the PSO algorithm, respectively, as shown in Table 3. Moreover, the corresponding percentage decrease in the case of WOA is $17.74 \%$ and $11.76 \%$ for the ISD and SD models, respectively.

Tables 4 and 5 show the reliability indicators and energy results at the optimal value of IR. Table 4 shows that the most reliable model is the TD PV model in terms of EENS, LOLP, and LPSP. Table 5 shows that the PV energy, obtained using PSO, of the ISD and SD models decreased by $9.3 \%$ and $3.23 \%$, respectively, from the TD realistic model. This means that the SD model is more accurate than the ISD model and close to the realistic TD model. Furthermore, the PV energy, obtained using WOA, of the ISD and SD models decreased by $10.47 \%$ and $7.26 \%$, respectively, from the TD model.

Table 4. Reliability indicators at the optimal value of IR.

\begin{tabular}{ccccccc}
\hline System Indicators & \multicolumn{2}{c}{ TD } & \multicolumn{2}{c}{ SD } & \multicolumn{2}{c}{ ISD } \\
\hline & PSO & WOA & PSO & WOA & PSO & WOA \\
\hline EENS (GWh) & 4.18192 & 4.20174 & 4.36339 & 4.60944 & 4.72389 & 4.65397 \\
LOLP & 0.09063 & 0.09113 & 0.09452 & 0.09961 & 0.10177 & 0.10038 \\
LPSP & 0.01442 & 0.01435 & 0.01473 & 0.014752 & 0.01467 & 0.01442 \\
\hline
\end{tabular}

Table 5. Detailed energy results at the optimal value of IR.

\begin{tabular}{ccccccc}
\hline Energy (GWh) & \multicolumn{2}{c}{ TD } & SD & \multicolumn{2}{c}{ ISD } \\
\hline & PSO & WOA & PSO & WOA & PSO & WOA \\
\hline $\mathrm{E}_{\mathrm{PVg}}$ & 16.17868 & 16.09858 & 15.65614 & 14.9292 & 14.67456 & 14.41378 \\
$\mathrm{E}_{\mathrm{Tg}}$ & 17.24111 & 17.33613 & 17.07264 & 16.8521 & 16.62589 & 17.03283 \\
$\mathrm{E}_{\text {brown }}$ & 8.87292 & 8.811006 & 9.02589 & 9.33189 & 9.51146 & 9.45935 \\
$\mathrm{E}_{\text {grid sales }}$ & 8.12711 & 8.099938 & 7.77055 & 7.37511 & 7.18828 & 7.21239 \\
$\mathrm{E}_{\mathrm{PVP}}$ & 3.55380 & 3.513006 & 3.18256 & 2.72173 & 2.45172 & 2.307472 \\
\hline
\end{tabular}

Thereby, the TD realistic model should be considered in large-scale RES solar applications. This is because it provides true and accurate size, energy, and reliability results. This will help the decision makers in their managerial environmental feasibility and reliability RES studies.

Here, the amount of GHG emissions and the corresponding emissions reduction were computed as shown in Table 6. The solutions obtained using PSO and WOA show that the TD solar model has the lowest GHG emissions and the highest ER compared with the ISD and SD solar models. For instance, it can be noticed regarding the PSO algorithm's solution that using the TD realistic solar model will mitigate the GHG emission by $1.72 \%$ and $7.2 \%$, compared with the SD and ISD models, respectively. Further, the corresponding ER of the TD model increased by $2.07 \%$ and $6.34 \%$, respectively, compared with both the SD and ISD solar models. This reinforces the recommendation that the TD model used in all PV-related studies will yield results in a more ecological RES. 
Table 6. Detailed energy and emission results corresponding to the optimal value of IR.

\begin{tabular}{ccccccc}
\hline Energy \& Emissions & \multicolumn{2}{c}{ TD } & \multicolumn{2}{c}{ SD } & \multicolumn{2}{c}{ ISD } \\
\hline & PSO & WOA & PSO & WOA & PSO & WOA \\
\hline E $_{\text {renewable }}(\mathrm{GWh})$ & 33.41979 & 33.43471 & 32.72878 & 31.78129 & 31.30045 & 31.44661 \\
$\mathrm{E}_{\text {brown }}(\mathrm{GWh})$ & 8.87292 & 8.811006 & 9.02589 & 9.33188 & 9.51146 & 9.45935 \\
ER (Gg/year) & 21.51982 & 21.52942 & 21.07486 & 20.4648 & 20.15512 & 20.24923 \\
GHG $_{\text {emissions }}(\mathrm{Gg} /$ year $)$ & 6.68792 & 6.641253 & 6.80322 & 7.03387 & 7.16922 & 7.129937 \\
\hline
\end{tabular}

\subsection{Uncertainty Analysis}

Uncertainty analysis measures the robustness of the system when one or more of the input data are varying. This includes different parameters, such as temperature, diode ideality factors, series, and leakage loss resistances. In this subsection, the uncertainty of the aforementioned parameters was tested for the TD realistic model as shown in Tables 7 and 8 . This is to present the impact of increasing or decreasing these parameters on RES. In Section 4.1, it was concluded that the solutions of both PSO and WOA are close to each other. Therefore, uncertainty assessment will be performed using PSO as a case validation.

Table 7. Percentage difference in $\%$ from the TD model for $\alpha$, Ta.

\begin{tabular}{ccccc}
\hline & \multicolumn{2}{c}{ Uncertainty of $\alpha$} & \multicolumn{2}{c}{ Uncertainty of $\mathbf{T a}$} \\
\hline & $\boldsymbol{\alpha}_{\mathbf{2}}=\mathbf{1 . 5}$ & $\boldsymbol{\alpha}_{\mathbf{2}}=\mathbf{1 . 8}$ & $\mathbf{T a} \mathbf{( + 1 0 \% )}$ & Ta (-10\%) \\
\hline IR & -0.05 & -0.07 & 0.04 & 0.03 \\
$\mathrm{~N}_{\mathrm{PV}}$ & 2.7 & 4.63 & -3.08 & 0.77 \\
$\mathrm{~V}_{\mathrm{LR}}$ & 0.04 & 0.04 & 0.04 & 0.04 \\
EENS & -1.13 & -1.23 & 2.63 & 1.0 \\
LOLP & -1.07 & -1.16 & 2.27 & 1.16 \\
LPSP & -3.33 & -4.72 & 2.43 & 1.94 \\
$\mathrm{E}_{\mathrm{PVg}}$ & 1.02 & 1.31 & -1.81 & 0.58 \\
\hline
\end{tabular}

Table 8. Percentage difference in \% from the TD model for $R_{s h}, R_{s}$.

\begin{tabular}{ccccc}
\hline & \multicolumn{2}{c}{ Uncertainty of $\boldsymbol{R}_{\boldsymbol{s}}$} & \multicolumn{2}{c}{ Uncertainty of $\boldsymbol{R}_{\boldsymbol{s} \boldsymbol{h}}$} \\
\hline & $\boldsymbol{R}_{\boldsymbol{s}} \mathbf{( + \mathbf { 1 0 } \% )}$ & $\boldsymbol{R}_{\boldsymbol{s}} \mathbf{( - 1 0 \% )}$ & $\boldsymbol{R}_{\boldsymbol{s h}} \mathbf{( + 1 0 \% )}$ & $\boldsymbol{R}_{\boldsymbol{s} \boldsymbol{h}} \mathbf{( - 1 0 \% )}$ \\
\hline IR & -0.03 & 0.03 & 0.03 & 0.03 \\
$\mathrm{~N}_{\mathrm{PV}}$ & 0.79 & -1.21 & -1.16 & 0.77 \\
$\mathrm{~V}_{\mathrm{LR}}$ & 0.04 & 0.04 & 0.04 & 0.04 \\
EENS & 0.57 & 0.58 & 1.09 & -0.45 \\
$\mathrm{LOLP}$ & 0.71 & 0.7 & 1.3 & -0.42 \\
$\mathrm{LPSP}$ & 1.94 & 2.22 & 1.94 & 1.94 \\
$\mathrm{E}_{\mathrm{PVg}}$ & -0.16 & -0.23 & -0.86 & 0.41 \\
\hline
\end{tabular}

Table 7 shows that the diode ideality factor has a major impact on the design of the RES. When $\alpha$ for diode 2 is equal to 1.8 , the PV panel percentage difference will be $4.63 \%$. Moreover, the series loss influences the RES more than the $R_{s h}$ as shown in Table 8. This is because the second diode current, affected by the $R_{s}$ as shown in Equation (4), will make the loss much larger if this resistance becomes larger. Furthermore, when the temperature increases, the PV energy will slightly decrease and vice versa.

Moreover, Table 9 shows the percentage change of the TD model at $\alpha_{2}=1.5$ and $\alpha_{2}=1.8$ from the other two models. As can be seen, this slight change in $\alpha$, due to recombination losses, has a large impact on the system sizing. The $\mathrm{N}_{\mathrm{PV}}$ and PV energy difference between the TD model at $\alpha_{2}=1.8$ and the ISD model are $20.36 \%$ and $7.65 \%$. Additionally, the GHG emissions will increase by $9.19 \%$, when 
using the ISD solar PV model. Therefore, neglecting the recombination loss will achieve inaccurate sizing and under the estimation ecological estimates for the RES.

Table 9. Uncertainty of $\alpha$ (in \%) due to recombination.

\begin{tabular}{ccccc}
\hline & \multicolumn{2}{c}{ SD } & \multicolumn{2}{c}{ ISD } \\
\hline & $\boldsymbol{\alpha}_{\mathbf{2}}=\mathbf{1 . 5}$ & $\boldsymbol{\alpha}_{\mathbf{2}}=\mathbf{1 . 8}$ & $\boldsymbol{\alpha}_{\mathbf{2}}=\mathbf{1 . 5}$ & $\boldsymbol{\alpha}_{\mathbf{2}}=\mathbf{1 . 8}$ \\
\hline IR & 0.02 & 0.04 & 0.04 & 0.06 \\
$\mathrm{~N}_{\mathrm{PV}}$ & -10.35 & -12 & -18.86 & -20.36 \\
$\mathrm{~V}_{\mathrm{LR}}$ & -0.19 & -0.19 & -0.51 & -0.51 \\
EENS & 5.53 & 5.64 & 14.25 & 14.36 \\
LOLP & 5.42 & 5.52 & 13.51 & 13.61 \\
LPSP & -1.14 & -2.45 & 1.77 & -2.85 \\
E & -4.21 & -4.48 & -10.21 & -10.47 \\
GHV $_{\text {emission }}$ & 3.5 & 3.61 & 9.07 & 9.19 \\
ER & -3.11 & -3.44 & -7.34 & -7.65 \\
\hline
\end{tabular}

\section{Conclusions}

In this paper, the impact of different PV models in a hybrid power system was investigated. The models considered were the two-diode (TD), single-diode (SD), and the ideal single-diode (ISD) models of the solar PV renewable energy system (RES). This study was also performed in terms of the reliability and emissions performance indicators. The RES considered included a PV array combined with a pumped hydro storage (PHS), which was investigated for the Al-Wehda dam, Irbid, Jordan. This impoundment was treated as the upper reservoir (UR) of the PHS of the proposed RES. Precise mathematical modelling was done on the output PV power. This was done by taking into account the recombination losses in the TD PV model. This led to a more realistic sizing and more accurate system evaluation. Furthermore, the hourly measured values of the load demand, solar irradiance, ambient temperature, and volumetric water flow rate were obtained from related institutions in Jordan.

The results were obtained using the PSO and WOA optimization algorithms. The results showed that the TD realistic model is more reliable than the other models. The PSO optimal value of IR was $98.558 \%$. The corresponding number of panels were 44,840 with a $65.052 \mathrm{M} \cdot \mathrm{m}^{3}$ volume of the lower reservoir. It was shown that the number of PV panels decreased by $16.67 \%$ and $7.93 \%$, respectively, for the ISD and SD compared with the TD realistic model. These high percentage differences could lead to improper sizing and underestimation of the RES. Moreover, the WOA optimal value of IR was $98.565 \%$. The percentage changes in $\mathrm{N}_{\mathrm{PV}}$ for WOA compared with PSO were $1.78 \%, 4.64 \%$, and $-0.5 \%$, for the ISD, SD, and TD models, respectively.

Further, the ecological impacts of the proposed models were assessed. It showed that the TD model is more ecological, using the two optimization algorithms, compared with the other models, resulting in an emissions reduction of 21.519 and $21.529 \mathrm{Gg} /$ year using PSO and WOA, respectively. These emissions reductions increased by $2.07 \%$ and $6.34 \%$, respectively, for the SD and ISD solar PV models referring to the PSO solution. Furthermore, the GHG emissions were found to be 6.6879 and $6.64125 \mathrm{Gg} /$ year in the case of the TD realistic model for PSO and WOA, respectively. These emissions increased for the SD and ISD models, respectively.

Finally, uncertainty analysis on the recombination losses, series and leakage losses, and temperature were performed in order to assess the robustness of the system using the PSO algorithm. This uncertainty analysis showed that the percentage difference of the number of PV panels for the realistic TD model decreased by $12 \%$ and $20.36 \%$ from the SD and ISD models, respectively, when the $\alpha_{2}$ values were 1.5 and 1.8. Further, the PV energy of the ISD and SD models decreased by $10.47 \%$ and $4.48 \%$, respectively, from the TD realistic model, when the $\alpha_{2}$ was 1.5 and 1.8. This means that the SD model is more accurate than the ISD model and closer to the realistic TD model. 
Author Contributions: H.M.K.A.-M. and S.K.M. contributed to the conception, design and wrote the paper; A.A. and O.S. help in the acquisition of data and revised the paper before the final submission; M.E. critically revised the paper. All authors have read and agreed to the published version of the manuscript.

Funding: This research received no external funding.

Conflicts of Interest: The authors declare no conflict of interest.

\section{Nomenclature}

STC Standard test conditions.

$f_{P V} \quad$ PV derating factor in \%.

$G(t) \quad$ Hourly solar irradiance in $\mathrm{kW} / \mathrm{m}^{2}$.

$T_{a m b}(t) \quad$ Hourly ambient temperature in ${ }^{\circ} \mathrm{C}$.

$I_{P h} \quad$ Photo current in A.

$I_{D 1} / I_{D 2} \quad$ Shockley diode currents due to diffusion and recombination mechanisms in A.

$I_{\text {sh }} \quad$ Current flowing in the shunt resistance in A.

$I_{01} / I_{O_{2}} \quad$ Diodes reverse saturation currents in A.

$I_{O_{\mathrm{STC}}} \quad$ Diodes reverse saturation currents at STC in A.

$\alpha_{1} / \alpha_{2} \quad$ Diodes ideality factors due to diffusion and recombination.

$V_{T} \quad$ Diode thermal voltages in V.

$R_{S} / R_{\text {sh }} \quad$ Series and shunt resistances in $\Omega$.

$N_{\text {ser }} \quad$ Number of PV modules connected in series per string.

$N_{\text {Par }} \quad$ Number of PV strings connected in parallel.

$P_{P V} \quad$ Rated PV power in W.

$P_{P V_{P}} \quad$ Surplus PV power transferred to the hydro pumps.

$\eta_{\text {inv }} \quad$ Efficiency of the inverter

$\dot{q}_{T}(t) \quad$ Hourly hydro turbine flow rate in $\mathrm{m}^{3} / \mathrm{s}$.

$h_{\text {net }} \quad$ Effective head altitude in $\mathrm{m}$.

$C_{T} \quad$ Turbine generating coefficient in $\mathrm{kg} / \mathrm{m} \cdot \mathrm{s}^{2}$.

$C_{P} \quad$ Turbine pumping coefficient in $\mathrm{m}^{3} \cdot \mathrm{s} / \mathrm{kg}$.

$V_{L R} \quad$ Volume of water stored in lower reservoir in $\mathrm{m}^{3}$.

POW Percentage of water in the lower reservoir (LR) in \%.

$\alpha \quad$ Evaporation and leakage loss in \%.

$\eta_{T} \quad$ Overall efficiency of the turbine-generator unit in \%.

$\eta_{P} \quad$ Overall pumping efficiency in \%.

$\rho \quad$ Density of water $\left(1000 \mathrm{~kg} / \mathrm{m}^{3}\right)$.

$g \quad$ Acceleration due to gravity $\left(9.8 \mathrm{~m} / \mathrm{s}^{2}\right)$.

$q_{\text {charge }} \quad$ Quantity of water released in the charging mode in $\mathrm{m}^{3}$.

$q_{\text {discharg }} \quad$ Quantity of water stored in the discharging mode in $\mathrm{m}^{3}$.

$E_{P V g} \quad$ Annual PV energy generated in MWh.

$E_{T g} \quad$ Annual hydro energy generated in MWh.

$E_{\text {grid sales }}$ Annual energy sales to the grid in MWh.

$E_{P V p} \quad$ Annual pumped PV energy in MWh.

$E_{\text {brown }} \quad$ Annual energy purchased from the utility grid in MWh.

$E_{\text {renewable }}$ Annual renewable energy in MWh.

EF Grid emission factor measured in $\mathrm{tCO}_{2} / \mathrm{MWh}$.

T\&D Transmission and distribution losses.

$L \quad$ Decimal equivalent of T\&D.

WOA Whale optimization algorithm.

PSO Particle swarm optimization.

LPSP Loss of power supply probability.

EENS Expected energy not served.

LOLP Loss of load probability.

IR Index of reliability. 


\section{References}

1. Suchitra, D.; Utthra, R.; Jegatheesan, R.; Tushar, B. Optimization of a PV-Diesel hybrid stand-alone system using multi-objective genetic algorithm. Int. J. Emerg. Res. Manag. Technol. 2013, 2, 68-76.

2. Ekren, O.; Ekren, B.Y. Size optimization of a PV/wind hybrid energy conversion system with battery storage using response surface methodology. Appl. Energy 2008, 85, 1086-1101. [CrossRef]

3. Feilat, E.; Azzam, S.; Al-Salaymeh, A. Impact of large PV and wind power plants on voltage and frequency stability of Jordan's national grid. Sustain. Cities Soc. 2018, 36, 257-271. [CrossRef]

4. Roy, P.; Majumder, A.; Chakraborty, N. Optimization of a stand-alone Solar PV-Wind-DG Hybrid System for Distributed Power Generation at Sagar Island. AIP Conf. Proc. 2010, 1298, 260-265.

5. Arabali, A.; Ghofrani, M.; Etezadi-Amoli, M.; Fadali, M.S. Stochastic performance assessment and sizing for a hybrid power system of solar/wind/energy storage. IEEE Trans. Sustain. Energy 2013, 5, 363-371. [CrossRef]

6. Ma, T.; Yang, H.; Lu, L.; Peng, J. Pumped storage-based standalone photovoltaic power generation system: Modeling and techno-economic optimization. Appl. Energy 2015, 137, 649-659. [CrossRef]

7. Ma, T.; Yang, H.; Lu, L.; Peng, J. Optimal design of an autonomous solar-wind-pumped storage power supply system. Appl. Energy 2015, 160, 728-736. [CrossRef]

8. Ma, T.; Yang, H.; Lu, L.; Peng, J. Technical feasibility study on a standalone hybrid solar-wind system with pumped hydro storage for a remote island in Hong Kong. Renew. Energy 2014, 69, 7-15. [CrossRef]

9. Pérez-Díaz, J.I.; Jiménez, J. Contribution of a pumped-storage hydropower plant to reduce the scheduling costs of an isolated power system with high wind power penetration. Energy 2016, 109, 92-104. [CrossRef]

10. Spyrou, I.D.; Anagnostopoulos, J.S. Design study of a stand-alone desalination system powered by renewable energy sources and a pumped storage unit. Desalination 2010, 257, 137-149. [CrossRef]

11. Mahmoud, Y.; Xiao, W.; Zeineldin, H. A simple approach to modeling and simulation of photovoltaic modules. IEEE Trans. Sustain. Energy 2011, 3, 185-186. [CrossRef]

12. Chin, V.J.; Salam, Z.; Ishaque, K. An accurate modelling of the two-diode model of PV module using a hybrid solution based on differential evolution. Energy Convers. Manag. 2016, 124, 42-50. [CrossRef]

13. Gupta, S.; Tiwari, H.; Fozdar, M.; Chandna, V. Development of a Two Diode Model for Photovoltaic Modules Suitable for Use in Simulation Studies. In Proceedings of the 2012 Asia-Pacific Power and Energy Engineering Conference, Shanghai, China, 27-29 March 2012.

14. Ishaque, K.; Salam, Z.; Taheri, H. Simple, fast and accurate two-diode model for photovoltaic modules. Sol. Energy Mater. Sol. Cells 2011, 95, 586-594. [CrossRef]

15. Tsai, H.-L.; Tu, C.-S.; Su, Y.-J. Development of Generalized Photovoltaic Model Using MATLAB/SIMULINK. In Proceedings of the World Congress on Engineering and Computer Science, San Francisco, CA, USA, 22-24 October 2008.

16. Attivissimo, F.; Adamo, F.; Carullo, A.; Lanzolla, A.M.L.; Spertino, F.; Vallan, A. On the performance of the double-diode model in estimating the maximum power point for different photovoltaic technologies. Measurement 2013, 46, 3549-3559. [CrossRef]

17. Ma, T.; Yang, H.; Lu, L. Development of a model to simulate the performance characteristics of crystalline silicon photovoltaic modules/strings/arrays. Sol. Energy 2014, 100, 31-41. [CrossRef]

18. Islam, M.A.; Merabet, A.; Beguenane, R.; Ibrahim, H. Modeling Solar Photovoltaic Cell and Simulated Performance Analysis of a 250W PV Module. In Proceedings of the 2013 IEEE Electrical Power \& Energy Conference, Halifax, NS, Canada, 21-23 August 2013.

19. Tamrakar, V.; Gupta, S.; Sawle, Y. Single-diode and two-diode PV cell modeling using Matlab for studying characteristics of solar cell under varying conditions. Electr. Comput. Eng. Int. J. 2015, 4, 67-77. [CrossRef]

20. Wang, L.; Singh, C. Compromise between Cost and Reliability in Optimum Design of an Autonomous Hybrid Power System Using Mixed-Integer PSO Algorithm. In Proceedings of the 2007 International Conference on Clean Electrical Power, Capri, Itlay, 21-23 May 2007.

21. Ekren, O.; Ekren, B.Y. Size optimization of a PV/wind hybrid energy conversion system with battery storage using simulated annealing. Appl. Energy 2010, 87, 592-598. [CrossRef]

22. Wang, L.; Singh, C. Multicriteria design of hybrid power generation systems based on a modified particle swarm optimization algorithm. IEEE Trans. Energy Convers. 2009, 24, 163-172. [CrossRef]

23. Kusakana, K.; Vermaak, H.J.; Numbi, B.P. Optimal operation control of hydrokineticbased hybrid systems. In Renewable Energy in the Service of Mankind Vol I; Springer: Cham, Switzerland, 2015; pp. 291-303. 
24. Tazvinga, H.; Zhu, B.; Xia, X. Optimal power flow management for distributed energy resources with batteries. Energy Convers. Manag. 2015, 102, 104-110. [CrossRef]

25. Belmili, H.; Haddadi, M.; Bacha, S.; Almi, M.F.; Bendib, B. Sizing stand-alone photovoltaic-wind hybrid system: Techno-economic analysis and optimization. Renew. Sustain. Energy Rev. 2014, 30, 821-832. [CrossRef]

26. Altarawneh, I.S.; Rawadieh, S.I.; Tarawneh, M.S.; Alrowwad, S.M.; Rimawi, F. Optimal tilt angle trajectory for maximizing solar energy potential in Ma'an area in Jordan. J. Renew. Sustain. Energy 2016, 8, 033701. [CrossRef]

27. Besheer, A.H.; Abdelaziz, A.Y. A Comparative Analysis for Different Kinds of Single Diode Model Photovoltaic Module. In Proceedings of the 2014 IEEE Innovative Smart Grid Technologies-Asia (ISGT ASIA), Kuala Lumpur, Malaysia, 20-23 May 2014.

28. Villalva, M.G.; Gazoli, J.R.; Filho, E.R. Comprehensive approach to modeling and simulation of photovoltaic arrays. IEEE Trans. Power Electron. 2009, 24, 1198-1208. [CrossRef]

29. Diaf, S.; Diaf, D.; Belhamel, M.; Haddadi, M.; Louche, A. A methodology for optimal sizing of autonomous hybrid PV/wind system. Energy Policy 2007, 35, 5708-5718. [CrossRef]

30. Eteiba, M.; Barakat, S.; Samy, M.M.; Wahba, W.I. Optimization of an off-grid PV/Biomass hybrid system with different battery technologies. Sustain. Cities Soc. 2018, 40, 713-727. [CrossRef]

31. Ma, T.; Yang, H.; Lu, L. Solar photovoltaic system modeling and performance prediction. Renew. Sustain. Energy Rev. 2014, 36, 304-315. [CrossRef]

32. Ma, T.; Yang, H.; Lu, L. Performance evaluation of a stand-alone photovoltaic system on an isolated island in Hong Kong. Appl. Energy 2013, 112, 663-672. [CrossRef]

33. Brihmat, F.; Mekhtoub, S. PV Cell Temperature/PV Power Output Relationships Homer Methodology Calculation. In Conférence Internationale des Energies Renouvelables" CIER'13"/International Journal of Scientific Research E Engineering Technology; International Publisher \&C. O: Sousse, Tunisie, 2014.

34. Kurobe, K.-I.; Matsunami, H. New two-diode model for detailed analysis of multicrystalline silicon solar cells. Jpn. J. Appl. Phys. 2005, 44, 8314. [CrossRef]

35. Cerofolini, G.; Polignano, M. Generation-recombination phenomena in almost ideal silicon p-n junctions. J. Appl. Phys. 1988, 64, 6349-6356. [CrossRef]

36. Hegedus, S.S.; Luque, A. Status, Trends, Challenges and the Bright Future of Solar Electricity from Photovoltaics. In Handbook of Photovoltaic Science and Engineering; John Wiley \& Sons: Chichester, UK; Hoboken, NJ, USA, 2003; pp. 1-43.

37. Ishaque, K.; Salam, Z.; Taheri, H. Accurate MATLAB simulink PV system simulator based on a two-diode model. J. Power Electron. 2011, 11, 179-187. [CrossRef]

38. Ramos Hernanz, J.; Campayo Martin, J.J.; Zamora Belver, I.; Larranaga Lesaka, J.; Zulueta Guerrero, E.; Puelles Perez, E. Modelling of Photovoltaic Module. In Proceedings of the International Conference on Renewable Energies and Power Quality (ICREPQ'10), Granada, Spain, 23-35 March 2010.

39. Mohammad, N.; Islam, M.; Karim, T.; Hossain, Q.D. Improved Solar Photovoltaic Array Model with FLC Based Maximum Power Point Tracking. Int. J. Electr. Comput. Eng. 2012, 2, 717-730. [CrossRef]

40. Kousksou, T.; Bruel, P.; Jamil, A.; El Rhafiki, T.; Zeraouli, Y. Energy storage: Applications and challenges. Sol. Energy Mater. Sol. Cells 2014, 120, 59-80. [CrossRef]

41. Margeta, J.; Glasnovic, Z. Theoretical settings of photovoltaic-hydro energy system for sustainable energy production. Sol. Energy 2012, 86, 972-982. [CrossRef]

42. Li, G.; Huang, Y.; Bie, Z. Reliability evaluation of smart distribution systems considering load rebound characteristics. IEEE Trans. Sustain. Energy 2018, 9, 1713-1721. [CrossRef]

43. Yang, H.; Lu, L.; Burnett, J. Weather data and probability analysis of hybrid photovoltaic-wind power generation systems in Hong Kong. Renew. Energy 2003, 28, 1813-1824. [CrossRef]

44. Olatomiwa Lanre, J. Optimal Planning and Design of Hybrid Renewable Energy System for Rural Healthcare Facilities/Olatomiwa Lanre Joseph; University of Malaya: Kuala Lumpur, Malaysia, 2016.

45. Jordan's Third National Communication on Climate Change; Ministry of Environment: Amman, Jordan, 2014.

46. Bank, A.D. Guidelines for Estimating Greenhouse Gas Emissions of Asian Development Bank Projects: Additional Guidance for Clean Energy Projects; Asian Development Bank: Mandaluyong, Philippines, 2017.

47. Eberhart, R.; Kennedy, J. A New Optimizer Using Particle Swarm Theory in MHS'95. In Proceedings of the Sixth International Symposium on Micro Machine and Human Science, Nagoya, Japan, 4-6 October 1995. 
48. Eberhart, R.C.; Shi, Y. Comparing Inertia Weights and Constriction Factors in Particle Swarm Optimization. In Proceedings of the 2000 Congress on Evolutionary Computation. CEC00 (Cat. No. 00TH8512), La Jolla, CA, USA, 16-19 July 2000.

49. Clerc, M.; Kennedy, J. The particle swarm-explosion, stability, and convergence in a multidimensional complex space. IEEE Trans. Evol. Comput. 2002, 6, 58-73. [CrossRef]

50. Liang, J.J.; Qin, A.K.; Suganthan, P.N.; Baskar, S. Comprehensive learning particle swarm optimizer for global optimization of multimodal functions. IEEE Trans. Evol. Comput. 2006, 10, 281-295. [CrossRef]

51. Gaing, Z.-L. Particle swarm optimization to solving the economic dispatch considering the generator constraints. IEEE Trans. Power Syst. 2003, 18, 1187-1195. [CrossRef]

52. AlRashidi, M.; El-Hawary, M. Applications of computational intelligence techniques for solving the revived optimal power flow problem. Electr. Power Syst. Res. 2009, 79, 694-702. [CrossRef]

53. Chen, C.; Duan, S.; Cai, T.; Liu, B.; Hu, G. Smart energy management system for optimal microgrid economic operation. IET Renew. Power Gener. 2011, 5, 258-267. [CrossRef]

54. Liu, L.; Zhou, F.; Tao, M.; Zhang, Z. A novel method for multi-targets ISAR imaging based on particle swarm optimization and modified CLEAN technique. IEEE Sens. J. 2015, 16, 97-108. [CrossRef]

55. Fu, Y.; Ding, M.; Zhou, C. Phase angle-encoded and quantum-behaved particle swarm optimization applied to three-dimensional route planning for UAV. IEEE Trans. Syst. Man Cybern. Part A Syst. Hum. 2011, 42, 511-526. [CrossRef]

56. Particle Swarm Optimization: Algorithm and Its Codes in Matlab. Available online: https://www.researchgate. net/publication/297245624_Particle_Swarm_Optimization_Algorithm_and_its_Codes_in_MATLAB (accessed on 21 May 2020).

57. Mirjalili, S.; Lewis, A. The whale optimization algorithm. Adv. Eng. Softw. 2016, 95, 51-67. [CrossRef]

(C) 2020 by the authors. Licensee MDPI, Basel, Switzerland. This article is an open access article distributed under the terms and conditions of the Creative Commons Attribution (CC BY) license (http://creativecommons.org/licenses/by/4.0/). 